\title{
Habitat heterogeneity supports epigeic arthropods after prescribed burning of dry grasslands
}

\author{
David D. Nagy ${ }^{\ddagger}$, Orsolya Valkó§${ }^{\S}$, Tibor Magura ${ }^{\S}$, Balázs Deák ${ }^{\S}$, Roland Horváthl, Bela Tóthmérész ${ }^{\S}$ \\ ‡ MTA-DE Biodiversity and Ecosystem Services Research Group, P.O. Box 71, Debrecen, Hungary \\ $\S$ University of Debrecen, Debrecen, Hungary \\ | university of Debrecen, Debrecen, Hungary
}

Corresponding author: David D. Nagy (david.nagy111@gmail.com)

Received: 24 Jul 2019 | Published: 29 Jul 2019

Citation: D. Nagy D, Valkó O, Magura T, Deák B, Horváth R, Tóthmérész B (2019) Habitat heterogeneity supports epigeic arthropods after prescribed burning of dry grasslands. ARPHA Conference Abstracts 2: e38500. https://doi.org/10.3897/aca.2.e38500

\begin{abstract}
Fire supports landscape openness; thus, prescribed burning could be an effective management in open landscapes. In this study we tested the response of arthropods (spider, ground beetle, rove beetle and woodlouse) to dormant-season prescribed burning in dry grassland patches. We hypothesized that the unburned patches support the arthropods recolonizing the burned patches; thus, fire causes no serious damage to the arthropod assemblages.

Epigeic arthropods (spider, ground beetle, rove beetle and woodlouse) were collected by unbaited pitfall traps containing ethylene glycol as a killing-preserving solution. Altogether 60 traps worked in 3 burnt and 3 control plots (10 traps/plot). Traps were emptied monthly from May to October in the year after burning. Collected arthropods were identified at species level using standard keys.

We found no significant difference between the burned and control plots for the abundance, species richness, and Shannon diversity of spiders, ground beetles, rove beetles and woodlice. Differences in total abundance, species richness and diversity of arthropods were also not significant between the burned and control plots. Among from 12 most abundant species, ten species was not affected by burning, while the abundance of
\end{abstract}


Titanoteca veteranica spider species increased and the abundance of Trochosa robusta spider species decreased in the burnt plots.

Microcaves and other unburned microhabitats in and around the burned patches serve as refuge for epigeic arthropods supporting the fast recolonization after prescribed burning, although the abundance of some epigeic spider species (Titanoteca veteranica, Trochosa robusta) was affected by burning. Our findigs revealed that prescribed burning is a potentially promising conservation method. We also highlighted that preservation of unburned microhabitats and surroundings of the managed patches is essential during the prescribed burning.

\section{Keywords}

biomass, fire, fuel load, response of the ecosystem, management, steppe

\section{Presenting author}

Dávid D. Nagy

\section{Presented at}

19th European Carabidologist Meeting, as a part of the poster session 